\title{
Some principles of the computer RFL workbook development: the interactive vocabulary and grammar elements
}

\author{
O. A. Gracheva - P. G. Matukhin - N. V. Komissarova- \\ O. V. Saltykova - P. A. Kopylova
}

DOI: 10.18355/XL.2019.12.01.08

\begin{abstract}
The article highlights the main principles of the development of interactive components of computer educational products to be used in RFL learning and TRFL training of foreign citizens of different categories in accordance with the state standards and regulations for all levels of RFL acquisition. The core of the proposed technique is the idea of using the Computer Workbook, which is a new interactive tool for TRFL certification preparation.

Key words: teaching, foreign citizens, state certification on Russian as a Foreign Language, GOST TRFL system, computer workbook, lexical-grammatical volume
\end{abstract}

\section{Introduction}

The processes of globalization in the economic sphere and other areas of human activity, as well as the widespread of computer systems with the Internet access, are coupled with the growing streams of business and personal communication worldwide. The integration of Russia into the world community causes an increase of interest in studying the Russian language in foreign countries.

The number of people under certification includes citizens of foreign countries interested in business cooperation, cultural contacts, and other kinds of cooperation with Russian companies and institutions that can provide work. To legally consolidate knowledge of Russian as a foreign language (RFL), they must have a state certificate on successfully completing Russian as a Foreign Language Test (TRFL) at levels A1, A2, B1, B2, C1, C2. Young people, arriving in Russia for obtaining higher education also need to master basic linguistic competencies in the field of RFL sufficient to study at Russian universities in the selected direction and level. The undergraduate degree training includes the mastery of RFL at levels A1, A2 and B1 (general threshold levels). In the future, the transition to each subsequent stage of training is followed by the state certification for a certain level of RFL.

Major changes have been made in this sector of education in recent times. Relevant governmental decrees have been adopted, the system of the state certification in RFL has been developed for various categories of foreign citizens. A number of special educational structures have been created to implement the new state policies in the sector of RFL training. All these innovations are aimed to support the TRFL certification of foreign citizens and create a system of RFL distance training. The same courses are offered by Russian Departments of Russian Centers of Science and Culture (RCSC) abroad. Their objective is to support the training for TRFL certification of foreign citizens in their native countries.

Distant and blended systems of educational communication facilitate independent self-study of learners. This leads to the need of creating textbooks of the new type. We have to create computer interactive simulations and self-evaluation tools to monitor the level of training achieved. All those tools should help verify students' proficiency and their readiness for certification.

This paper is aimed at the consideration of some basic principles of the development of training interactive components of a computer educational information products that are to be used in RFL learning and TRFL training of foreign citizens in

XLinguae, Volume 12 Issue 1, January 2019, ISSN 1337-8384, eISSN 2453-711X 
accordance with the GOST requirements (the Standards \& Regulations of the Russian Federation).

\section{Relevance}

Special training is required for foreign citizens of different categories to obtain the TRFL certificate of each level. The training includes grammar and lexis language skills development as well as 4 other aspects of communication which is reading, listening, speaking, and writing. Computer technologies are increasingly gaining prominent popularity in language training. Lots of educators and scientists actively support the design and use of distance learning platforms. For example, Sumit Goyal says: "Presently the concept of E-learning is becoming very popular as the numbers of internet savvy users are increasing. E-learning gives the advantage of $24 \times 7$ and 365 days year-round access as compared to Instructor-Led Training, which is a one-time class that must be scheduled. E-learning is cost-effective as course content once developed could be easily used and modified for teaching and training" (Goyal, 2012). The use of new educational systems and training technologies in RFL teaching is associated with certain changes in the teacher's role in the process of educational communication. The English e-teacher faces the role of the learning process manager. While having trained for the TRKI certification, foreign citizens need to systematize their knowledge in vocabulary and grammar according to the appropriate TRFL level. They are supposed to practice their skills and abilities doing traditional exercises as well as using computer technologies and special equipment. The thoroughness of defining and ranging the words in speech patterns of the Russian language is dictated by the fact that it is the basics of the language. And the way how foreign citizens will be able to navigate the basic system of the Russian language depends on how successfully they will develop and pass their certification testing of the first (A1) and other subsequent levels. The importance of information and communication technologies in teaching a foreign language to learning grammar was underlined by Eva Svarbova. So, E.Svarbova emphasizes the important role of computer multimedia applications in a foreign language teaching: "Information and communication technologies offer a wide range of possibilities for acquiring and transmitting knowledge. Using multimedia, the teaching and learning process becomes more active, making the teacher a real guide of the educational process. The attention is focused on the student who is responsible for his progress himself. It is also interesting to examine how the multimedia computer application can help us, educators, in teaching a foreign language" (Svarbova, 2008).

The above-mentioned experts, as well as many others in the field of linguistic disciplines teaching, testify to the relevance of studying new systems and technologies regarding their application for the training of foreign citizens of different categories for the state TRFL certification.

\section{Problem}

The structure of the certification tests for each level of the GOST TRFL system includes 5 subtests:

- Vocabulary and Grammar,

- Listening Comprehension,

- Reading,

- Speaking,

- Writing.

The TRFL standards determine the content of each subtest. They establish quality requirements for proficiency in RFL, as well as quantitative indicators for each level. 
This includes lexical minimum, maximum and minimum percentage of evaluation of the test completion.

The TRFL standard defines the minimum "passing" score for each subtest at all levels. Usually, it is equal to $66 \%$. The level of $100 \%$ implies a deep knowledge. This scale serves as a good benchmark.

To provide candidates with effective training for certification, it is necessary to develop new information products. Such products are intended to get students acquainted with the requirements of the TRFL GOST for the appropriate level. Special products are needed to support the process of test preparation. Traditionally, these functions have been performed by printed handbooks, compilations of standard test tasks, manuals. But nowadays there is a rapid growth of new forms of educational communication in the RFL teaching sector. Educational institutions and commercial organizations develop a network of sites, offering RFL training and TRFL certification in a distant or blended mode. In this regard, the issue of the design of clusters of educational products for Russian teaching and learning is to be focused primarily on computer and online communication. They should be applicable both for TRFL training and certification procedure as well.

Trying to find the appropriate solution, we should focus on the following tasks:

-Development of methods of preparation for the state TRFL certification with the use of the new computer and network technologies and systems of telecommunication.

-Selection of learning content for each level of the TRFL, taking into account the requirements of relevant GOST.

-The choice of software for implementation of training of foreign citizens of different categories for the certification.

-Preparation of special guidelines for each level of certification.

-Development of computer and online support systems of preparation for certification, including information materials, manuals, simulations and model testing kits.

-Testing and analysis of the results of the use of new forms of training of foreign citizens for certification.

-Modification of the research findings.

Further, in this paper, we're going to present an overview of some of the results obtained during the development of recommendations for preparing for the TRFL certification at the TEL/A1 level with the primary focus on computer and mobile communication of all participants of the process of the RFL teaching and learning.

\section{Methods}

The core of the technique is the idea of using the Computer workbook - a new instrument in the process of training foreign citizens of different categories for the TRFL certification. This tool seems to be a new electronic version of the classic workbook on the Russian language for beginners, which was used for many years at the preparatory department of training foreign citizens arriving in Russia to receive higher education, those who do not speak Russian. Such students should take a 1-year course of language and general education before the admission to the first year of University. The transition to a computer and online forms is stimulated not only by the massive spread of the Internet communication devices but by a higher efficiency of the special computer educational systems. This market currently shows rapid growth. The TRFL GOST provides regulation of the content of such information products. It sets the parameters for the objective of a unified control study of Russian at all levels of the state certification. The key is the requirement of independence of test results from the place, time and form of the RFL studies, as well as of other factors of the process of preparation for certification (The Lexical Minimum in Russian as a Foreign Language. The First Certification Level. Common Ownership. $9^{\text {th }}$ edition. St. Petersburg: Zlatoust.:2017). Further, we'll present an excerpt from this

XLinguae, Volume 12 Issue 1, January 2019, ISSN 1337-8384, eISSN 2453-711X 
document, despite the volume limit of the paper. We believe such extensive quotation can be justified in view of its importance for our research.

"In accordance with the requirements of GOST TRFL, the lexical minimum of elementary level A1 is intended to provide foreign citizens the following opportunities:

to read

- specially composed or adapted texts of up to 150 words of everyday life, educational, socio-cultural sphere;

— maps and signs with names of cities, squares, streets, etc.

— signs in stores, billboards, announcements about tours and other cultural events;

to understand by ear

- dialogues (up to 60 words)

— monologues (up to 120 words)

- ads in transport;

to initiate a dialogue and to respond appropriately to the interlocutor;

to express a wish, request, agreement (disagreement), gratitude, etc.;

to build an oral monologue utterance on the basis of the text (max 180 words) to express own attitude to the action or fact;

to produce their own coherent statements in accordance with the proposed topic (at least 7 sentences);

to construct a written monologue statement ( 7 sentences) of a productive character in accordance with the communication setting based on the given questions;

to construct the written monologue statement of a reproductive character on the basis of the text (up to 200 words).

According to the State Standard of RFL, at the elementary level foreign citizens should be able to realize the communicative needs under the following topics: "Story", "Work", "Training", "Time", "Leisure", "Recreation" and "Family". The words included into the minimum, also give the opportunity to communicate in such basic survival situations as "Food", "Health", "Weather", "Transport", "Shopping", "The City, orientation in the city."

The solution to these communicative tasks at level Al is provided by the lexicon with a volume of 780 units. The communicative patterns include denoting the time of day, days of week, months, modes of transport, municipal institutions (museum, theatre), professions, sciences (actor, history); cardinal numbers; designation of the members of the family, household items (knife, glasses), food (rice, juice), essential action (run, read, walk), etc. The vocabulary includes some amount of academic notions to be able to continue studying the language at the more advanced level). Therefore, the dictionary contains such words as a teacher, textbook, etc. Moreover, the minimum contains different formulas of speech etiquette of the Russian language that is necessary to solve vital communication problems.

Thus, the main part of the thesaurus consists of basic words, which reflect fundamental concepts. In the selection of vocabulary, the principle of consistency has been taken into consideration. So, the vocabulary book contains basic terms of kinship, although not all of them have the same frequency. But if the foreign learners should understand the words grandma and grandpa, they have to understand the words grandson and granddaughter. It is this principle, this way of presenting lexical material that ensures the formation of the necessary cognitive base.

The basic vocabulary book doesn't include names of continents and countries, as they constitute a thematic group of the second part of the book. The content of this group may change depending on the political and economic situation in the world, place, and purpose of language learning, as well as the interests of foreign people studying the Russian language. These words, therefore, must belong to the $10 \%$ of the vocabulary presented in every textbook in addition to the lexical minimum." 
Here we can clearly see some defined quantitative parameters that should be considered in developing computer component manuals. An important consequence of the above-cited regulatory document is the provision that the study of vocabulary and grammar of RFL should be considered as the base for further formation and development of the linguistic competence of foreign citizens not only at level A1 but also at all subsequent stages of development of speaking skills. In the process of training for A1 and other modules, the RFL teachers can be recommended to introduce a new lexical and grammar material step by step, following the methodological principle "from simple to complex". To prepare students to pass the exam in RFL it is essential to expand the amounts of the language grammar space compared to the required level of testing and to add new types of tasks for learning. If the set of standardized GOST tests is the top of the iceberg, the process of preparation to them is the underwater part of the iceberg, which extremely exceeds the surface part.

Then the question arises about the principles of the design and development of computer workbooks for each level of certification. These workbooks, on the one hand, would help foreign citizens to fill in the gaps in their knowledge of the Russian language. On the other hand, they would be interactive tools that would effectively prepare them for standardized tests, as the material composed in the computer format would cover all lexical and grammatical topics. The material should be presented step by step, in accordance with the classical methods of RFL teaching. At the same time, we expect to use the opportunities provided by new hypertext forms of innovative products for educational purposes. It is possible to include in the workbook the hyperlinks connecting the primary content with blocks of additional materials such as teacher network resources, libraries, storage files, movies, books, audio recordings and so on, as well as special online language training support systems.

In addition to the traditional forms of textbooks used in the process of learning and preparation for TRFL, we must use innovative technologies for automated control and distant self-control of students. One of such elements of the overall system of information products is a set of computer workbooks (CW) for each level of certification, which include the optimum volume of the material and would help foreign citizens to effectively master RFL vocabulary and grammar under an appropriate level.

Thanks to computer technology the teacher will be able to design the set on his/her own, as the workbook of each previous level serves as a base for constructing the workbook for the next level. This scheme is characterized by continuity, which means that the study of the material at a higher level is followed by repetitions of the previous one, which now is good for practice. It can be assumed, that the new material smoothly integrated with a matrix of familiar things, can be acquired much easier.

\section{Results}

To verify the hypothesis about the possibility of creating CW by RFL teachers themselves and effectiveness to training foreign citizens for TRFL, several sets of interactive elements have been created. At the same, there have been developed recommendations for RFL teachers, who use this kind of CW in the process of TRFL preparation. The $\mathrm{CW}$ contains the set of exercises that the teacher can pick up and form another set depending on the learning goals and outcomes. Each model of CW is supported with specially designed computer simulators (quizzes) for each set of tasks. The quizzes help foreign citizens achieve good results by practicing the right answers to the test questions and repeating the attempts in the mode of self-control. This model will facilitate the enhancing students' language skills and abilities, bringing them to automatism.

XLinguae, Volume 12 Issue 1, January 2019, ISSN 1337-8384, eISSN 2453-711X 
In the first phase of the project developed a thorough study of the requirements of the entire TRFL GOST system and analysis of the sample tests was performed. It is revealed that in tests of $\mathrm{A} 1, \mathrm{~A} 2, \mathrm{~B} 1$ levels the dominating tasks are on vocabulary, grammar, and reading. In tests for B2, C1, C2 the dominating tasks are on listening, speaking, writing. Taking it into consideration, the recommendations for teachers have been developed.

Of particular interest, among other things, is the quantification and comparison of the requirements of the TRFL GOST system to the amounts of lexical material introduced for each level. These indicators are represented in the table below. To make the understanding of digital data easier, we present the appropriate diagram reflecting the ratio of the volume at different levels, established by the relevant standards

Table 1. Lexical minima of the TRFL levels

\begin{tabular}{|c|c|c|}
\hline \multirow[t]{2}{*}{ TRFL-Level $\cdot Q$} & \multicolumn{2}{|c|}{ Lexmin. (units)o } \\
\hline & Generalo & Active: \\
\hline TЭУ/A1/Breakthrough/Novices & \multicolumn{2}{|c|}{7800} \\
\hline TБYM/A1/Brealthrough/Novices & \multicolumn{2}{|c|}{8500} \\
\hline TБY/A2/-Waystage/Intermediate-Higho & \multicolumn{2}{|c|}{13000} \\
\hline TPKИ-I/B1/Threshold $\$$ & \multicolumn{2}{|c|}{23000} \\
\hline TPKИ-II/B2/Vantage/Advancedo & $10000 \%$ & 60000 \\
\hline $\begin{array}{l}\text { TPKИ-III/C1/. Effective Operational- Proficiency/ } \\
\text { Advanced-Pluso }\end{array}$ & 120000 & 70000 \\
\hline TРКИ-IV/C2/Good·User/Native: & 200000 & 80000 \\
\hline
\end{tabular}

The diagram below illustrates the ratio of the volume of the lexical minimum for the whole range of levels. It should be noted that the TRFL standards don't present separate general and active vocabulary for levels A1-B1. Therefore, the height of the figures indicating them in this chart is equal in both rows.

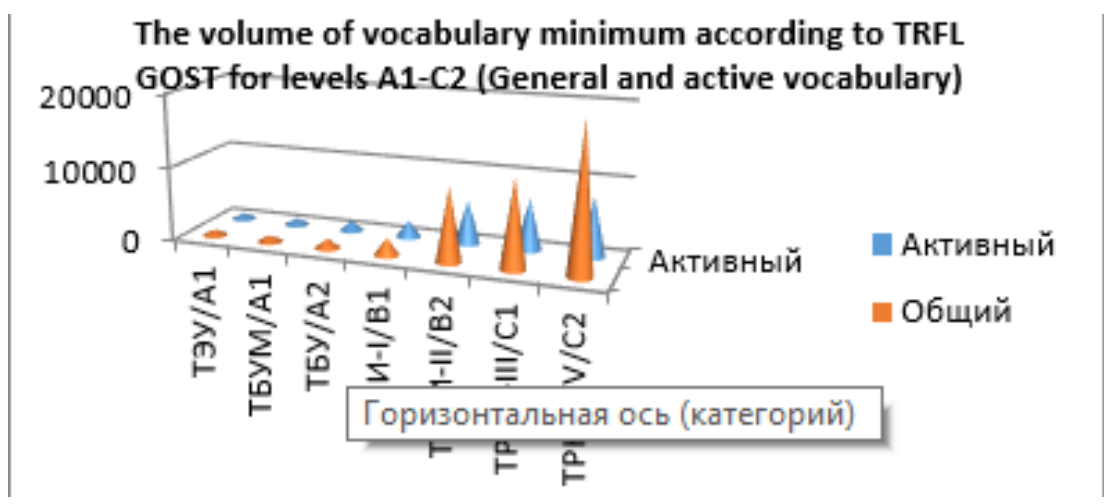

Figure 1: Lexical minima for levels A1-C2.

Figure 1 demonstrates the ratio of the volume of the vocabulary for all levels of certification. It shows the high volumes for levels of the profession (B2-C2) compared with the levels of basic knowledge (A1-B1). The next diagram demonstrates the volume ratio of the lexical minimum for levels of the group A1-B1 separately. 
The numeric data and their visual representation in the diagrams shown here demonstrate that with the change of levels of certification the minimum vocabulary shows a nonlinear increase. This observation is of special importance for our work. It helps to estimate the volume of the teacher's work on the stage of the computer implementation of educational content for each level. It is especially important to ensure compliance with the scope of vocabulary with the requirements of the appropriate TRFL GOST levels. Taking these data into account, we can estimate the volume of efforts on the preparation of dictionaries, simulators, and test items.

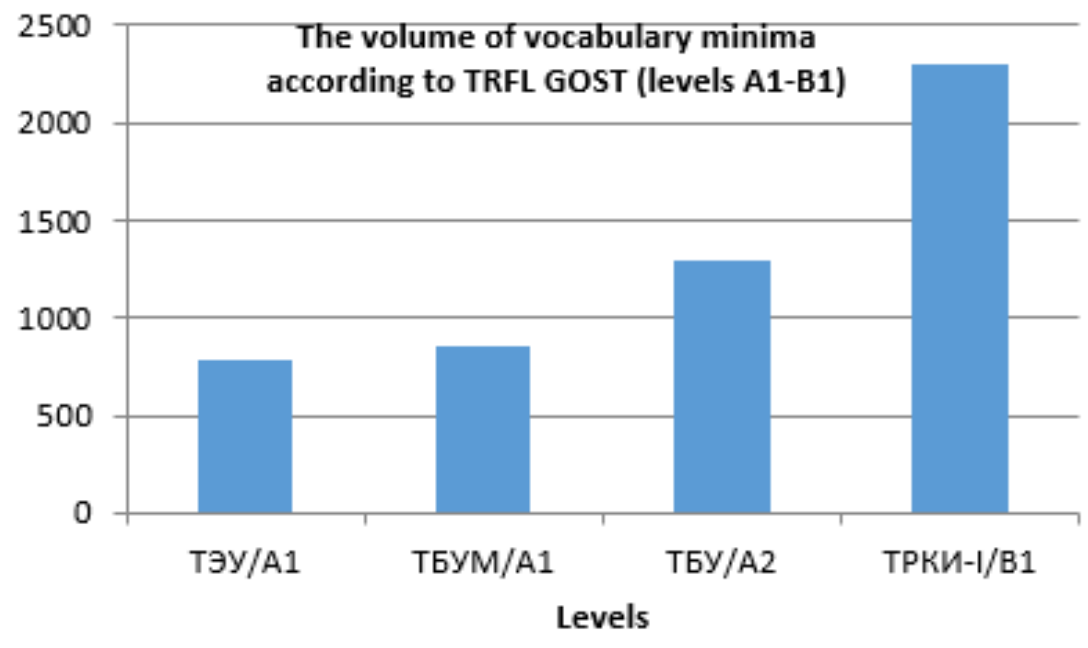

Figure 2: Lexical minima for levels A1-B1.

Such a drastic growth in a minimal vocabulary when moving from level to level brings about the need to define how the array of vocabulary for each next level can be formed and if it should include the entire amount of the previous level (inheritance and extension) or renew every time. Making a choice between these two diagrams (inheritance, extension, and creation of new sets of vocabulary for each level) we've chosen the first. This decision has been made due to the fact that it does not contradict the standards. Moreover, it will save labor costs of the teacher for the creation of original products. Moreover, it's most important that the first approach would allow the method of knowledge bridges between levels to be used as the most efficient for the purpose of the project. It makes it possible for the learners when encountering on a higher level of training familiar patterns studied before on the previous level of training, they could perceive the Russian language as a whole system, but not as a collection of separate modules not overlapping each other.

It is obvious that the competence of foreign citizens in terms of acquiring such skills as listening, speaking and writing depends on their knowledge of vocabulary and grammar of the RFL on the appropriate level. In order to improve their understanding of the texts in the Russian language, their speaking and writing skills and abilities to formulate the thought, they ought to practice intensive reading, which could place the student in the foreign language world and "feed" his mind both formally and substantively. When reading, the student gets acquainted with the sentence structure, vocabulary, grammar relations between words. The deficit of reading practice would make it difficult or even impossible for a foreign citizen to understand oral speech, formulate thoughts in Russian and, subsequently, create any texts. Without thoughtful

XLinguae, Volume 12 Issue 1, January 2019, ISSN 1337-8384, eISSN 2453-711X 
reading practice, you cannot master listening, speaking and writing skills. Therefore, preparation for tests of any level should begin with a thorough study of vocabulary, organization, thematic contour of words distribution at synonymous and antonymic ranks, forming derivational chains, etc. through texts.

Analyzing the ways of development of the technique of designing computer workbooks, simulators, and tests, we face the necessity to define clearly the concept of "lexical unit". It is of crucial importance for our research. It was observed that the current TRFL standards do not contain a clear definition of this concept. At the same time, depending on how it is interpreted, the degree of readiness of the examinee to the certification should be defined and estimated, as well as the teacher's workload on the creation of the toolkit and the workload of a student to cover a substantial component of the workbook. The correct definition of the term mentioned would help avoid failures, excessive requirements and costs of labor in preparation for the test. We propose the following approach.

A lexical unit is an element of the lexical level of language, which has a bilateral character. It includes a content level and the expression level. It also involves grammatical design and performs a nominative function. The lexical unit refers to all forms and meanings of the word.

In speech patterns, this abstract unit can be realized in some specific units. For a specific context, only one meaning and one-word form out of the many possibilities is to be selected. If in the Russian language different forms of a particular word are the same lexical unit, for the teacher-developer (programmer) who creates quizzes, those are the individual components of the data array, the total volume of which affects the amount of programming and student training time. Thus, we come to an important conclusion that assigned by the TRFL-TEL/A1 the volume of 780 lexical units should not be confined to a set of nouns and adjectives in the nominative case, verbs in the infinitive form and some items from other parts of speech. Their total number is rather small and can be easily implemented in interactive computer formats. But if we take the definition above, the actual amount of CW content increases significantly. E.g., the noun cases increase the amount in 6 times. The similar situation is with adjectives, verbs and other parts of speech.

The principle of the completeness of computer educational system and the given above definition of the lexical unit lead developers of new educational products to provide their students every opportunity to fully explore all the aspects of Russian as a foreign language up to the high level of language proficiency. Once expending a lot of effort to develop such an integrated system, the teacher of RFL will provide its students the environment, in which they can fully realize their aspirations and rely only on their own strength, desires, and needs.

The set of the exercises and simulators of CW include standardized tests. Having this tool, teachers can easily conduct monitoring and final inspection. For students, it's a good tool to estimate the level of their knowledge autonomously. It's also significant that in the process of preparation for TRFL using CWs, foreign learners have an opportunity to develop their basic language competences.

While trying to identify the components of the innovative complex for TRFL system certification preparation with the use of $\mathrm{CW}$ for training and test materials design, we concluded that teachers should follow a number of basic principles. First and foremost, we must consider that the function of any task in a subtest is to determine the degree of examinee's knowledge of lexicon, grammar and 4 aspects of speech activity.

Undoubtedly, tests cannot be considered as a universal form of verification of knowledge, suitable for all occasions. But TRFL is the most objective and technologically advanced form of mass control of specific knowledge prescribed by the standards for each level of RFL. An effective test is considered as the result of the fusion of the content of the tasks with the most suitable form for them. Depending on 
the knowledge controlled, the appropriate type of test items must be chosen - open or closed and their subtypes.

Developing principles of formation of interactive materials for computer workbook of the TRFL-TEL/A1, we have substantially relied on the statutory provisions declared by the "Lexical minimum..." cited above. In particular, the selection of lexical units was made following such criteria as:

1) no stylistic limit;

2) the ability to log in a phrase;

3) semantic value (the ability of words to label common objects and phenomena);

4) the ability of words to form partnerships (words with high word-building capacity are used to create potential dictionary);

5) frequency (taking into account the overall frequency at the frequency dictionaries on the use of textbooks in RFL "theme" frequency).

Based on the principles of modern didactics of RFL, considering the applicable regulations and the capabilities of new computer systems and technologies of language learning, we can formulate the following principles of development of training of foreign citizens at the stage of preparation to certification of RFL for TEL/A1 support systems.

1. Scientific, systematic and innovative approach to linguistic testing. This principle is understood as the compliance of the $\mathrm{CW}$ exercises and tests to the achievements of modern RFL linguistics, the requirements of the TRFL GOST of the appropriate level, principles of testology and capabilities of modern computer technology through a holistic, multilateral coverage of the studied subject. This principle allows us to build knowledge testing in accordance with the current state of the development of language science, RFL linguistics, and up-to-date hardware and software. Each task, aimed to check some special part of knowledge in the whole system, must contact the other common structure of knowledge and language competences.

2. Objectivity, content-relevance and test balance. This principle implies the inclusion in the certification test those elements of knowledge amenable to rational, but not the intuitive-shaped argument in the measurement of the language training that form the basis of genuine competences, without which it is impossible to assess if a foreign citizen has acquired the relevant skills to complete the subtests correctly. TRFL tasks should require accurate answers and reflect key aspects of the level, but CWs can include various exercises.

3. Test conformity, or compliance of the number and complexity of tasks with the level of certification. Subtests should not deviate from the requirements of GOST on this level. To enhance the guarantee of passing the test well it's possible to expand and deepen $\mathrm{CW}$ content.

4. The representativeness of the test. For evaluation of language competence of the test, when designing the test and creating the $\mathrm{WC}$, developers must pay attention to the sufficiency of the number of tasks that is related to representativeness: the more tasks and areas of the knowledge are check, the more representative are the results. The test needs to represent the idea of the level measurement.

5. Augmentation. This principle implies the use of ready-made exercises as components of the higher levels with the ability to smoothly make the language transition to the next level according to the GOST with the inclusion of existing tests. The result of the application of this technique is the repetition and consolidation of the material studied, as well as the effective assimilation of new material on the background of contextual information that allows us to quickly build $\mathrm{CW}$ software (quiz).

6 . The variability of the test. After the first application of the test, its content becomes known to the examinees. Thus, there's a need to create multiple versions of tasks,

XLinguae, Volume 12 Issue 1, January 2019, ISSN 1337-8384, eISSN 2453-711X 
which should be roughly equal in difficulty. It is the computer workbook that provides the use of the original set of materials to create multiple tests.

7. Quantification. This principle is associated with a quantitative estimation of the test complexity. From the point of view of the theory of information, the notion of the difficulty of the test task can be linked with the amount of information, which a Respondent should have to answer the question correctly. Test questions are divided into 2 main groups. This is the Open-ended questions (multiple choice from a set of options) and Closed type (writing the response in the blank). The main difference is the various entropy, i.e. the number of possible answers to the question. The amount of information needed to answer the Open-ended questions is limited and can be calculated in bits. The volume of Closed-ended question is almost close to the infinitely large value. Tasks with a finite entropy are represented by the quiz (the clear choice is the only correct option of the set), the selection of Yes-No alternative (examinees make a choice in the field of 2 possible options, it's a single bit to the question), the multiple choice of a number of correct answers, the complex choice from a bulk.

Tests and WC exercises contain such types of tasks as matching (establishing correspondences of two sets' elements) and sequencing (making different sequences of letters in words, words in sentences, paragraphs in the text, etc.).

8. Workability. The exercises are designed for $\mathrm{CW}$, and therefore all the capabilities of the software should be used, and all the constraints are taken into account.

9. Polymorphism - the ability to convert source material into forms suitable for automated import/export in various computer and on-line educational system.

10. The priority of the laws of language in the development of classroom informatization technology. It is impossible to process arrays of language units in one computer technological operation; you must first group them based on the linguistic principle.

11. Inheriting or building the systems of training and testing on the principle of inclusion arrays of the vocabulary of the previous levels in the subsequent ones.

Based on the above CW interactive components design principles, there have been developed some guidelines for writing tests to prepare for language certification of foreign citizens with the requirements of the TRFL GOST. They are

- clear wording of test items, simple interpretation;

- the brief wording of test items, without complex sentences, participial constructions and introductory words;

-formulation of test tasks without repetition and double negatives;

-restriction in the wording of the questions and answers tips;

-no prompts and judgments in question;

-formulation of key concepts at the beginning of the sentence;

-a sufficient number of answers ( 2 or 4-6 options in open questions; 4-5 in matching; 4-8 for sequencing);

- illustrations, diagrams to support tasks;

-a sufficient number of tasks of different difficulty levels for maximum objectivity and reliability of test results;

- alternating types of tasks "from simple to difficult".

- optimal use of tasks with alternatives (Yes-No);

- no trapping tasks or provocative questions.

Of course, the above list is not considered to be exhaustive. It's open to editing and modification. We'd like to proceed with the development of our project and would assume its full understanding and overall discussion.

\section{Conclusion}

Taking into consideration the main goal of the project, which is to develop a computer workbook for preparation of foreign citizens - students of preparatory faculties of 
Russian universities, in educational institutions, in classrooms of Russian centers of science and culture abroad, in person or remotely, for successfully passing the state RFL assessment with the requirements of the new Standards of GOST TRFL system, it is possible to propose the following statements. The formulated principles of designing training simulations and $\mathrm{CW}$ tests, as well as recommendations for its implementation and development, provide RFL teachers wide possibilities in the design of proprietary educational tools and technologies based on modern technical means of support of the learning process.

At the same time, the introduction of the TRFL system to foreign citizens of different categories through the development of learning techniques based on computer information products based on the above principles with the use of self-control will help improve their general educational competence. The students will be able to choose the appropriate program and the system of support to study the language at any level at a higher stage of training.

The publication has been prepared with the support of the "RUDN University Program 5-100" project.

\section{Bibliographic references}

THE CONCEPT OF STATE SUPPORT AND PROMOTION OF THE RUSSIAN LANGUAGE ABROAD" (Approved by the President of the Russian Federation on 03.11.2015 N Pr-2283).

FEDERAL LAW No. 273-FZ of December 29, 2012 "On Education in the Russian Federation" of December 29, 2012, No. 273-FZ.

FEDERAL LAW No. 53-FZ of 01.06.2005 (as Amended on 05/05/2014) "On the State Language of the Russian Federation".

DECREE OF THE GOVERNMENT of the Russian Federation of December 20, 2014 No. 2647-r "Approve the Attached Concept of the Federal Target Program "Russian Language" for 2016-2020".

ORDER OF THE MINISTRY OF EDUCATION AND SCIENCE OF RUSSIA from 14.12.2009 № 463 "On the Approval of Federal-State Requirements for Russian as a Foreign Language".

ORDER OF THE MINISTRY OF EDUCATION AND SCIENCE OF RUSSIA from March 24, 2010 No. 207 "On Approval of the Procedure for State Testing of Foreign Citizens and Non-Citizens in Russian as a Foreign Language".

ORDER OF THE MINISTRY OF EDUCATION AND SCIENCE OF RUSSIA from 01.04.2014 №255 "On Approval of the Levels of Proficiency in Russian as a Foreign Language and Requirements for Them".

BALYKHINA, T.M. 2007. What is the Russian Test? Russian State System for Testing the Russian Language. Moscow.

BALYKHINA, T.M. 2007. Basics of Test Theory and Testing Practice (in the Aspect of Russian as a Foreign Language). Moscow.

BOLDYREV, E.V. 2017. On the Promotion of the Russian Language Abroad. The Speech at the II All-Russian Scientific and Practical Conference "Actual Issues of the Implementation of Educational Programs in Preparatory Faculties for Foreign Citizens". Moscow: Pushkin SRLI, September 6-7.

GOYAL, S. 2012. E-Learning: Future of Education. Journal of Education and Learning. Vol.6 (2), pp. 239-242.

KHAVRONINA, S.A. - BALYKHINA, T.M., etc. 2002. Traditions and Innovations in the Professional Work of a Teacher of Russian as a Foreign Language: Monograph. Moscow.

KHAVRONINA, S.A. - BALYKHINA, T.M. 2000. Innovative Educational and Methodical Complex "Russian as a Foreign Language" [Electronic resource].

XLinguae, Volume 12 Issue 1, January 2019, ISSN 1337-8384, eISSN 2453-711X 
Textbook. Moscow: Publishing House of the Peoples Friendship University of Russia, $198 \mathrm{p}$.

KOMISSAROVA, N.V. - GREBENSHCHIKOVA A.V. 2005. The Use of New IT Capacities in Training Interpreters. Self -Determination of a Person. New Approaches and Technologies. Proceedings of the $2^{\text {nd }}$ International Scientific and Practical Conference, Dedicated to the Memory of Professor A.D. Sazonov. pp. 140-141.

KOMISSAROVA, N.V. - MATUKHIN, P.G. - GRACHEVA, O.A. SALTYKOVA, O.V. 2017. The Set of Teaching Materials for TRFL Certification Preparation. Part 9. Legal Fundamentals of RFL Teaching and Testing of Foreign Citizens in Russian Centers of Science and Culture Abroad. Chronicles of the United Fund of Electronic Resources Science and Education, No. 9 (100), 32 p.

MITROFANOVA, O.D. - KOSTOMAROV, V.G., etc. 1990. Methods of Teaching Russian as a Foreign Language. Moscow.

RADCHENKO, O.A. 2017. Remote Testing of the Russian Language as a Foreign Language. The Speech at the II All-Russian Scientific and Practical Conference "Actual Issues of the Implementation of Educational Programs in Preparatory Faculties for Foreign Citizens". Moscow: Pushkin SRLI, September 6-7.

SOBOLEVA, N. I. - VOLKOV, S. U. - IVANOVA, A. S. 2008. Progress. Russian Language Textbook. Elementary Level. Moscow: RUDN.

SVARBOVA, E. 2008. Multimedia vo vyucovani francuzskeho jazyka Massmedia in Teaching French. Vol.1, Iss.1, pp. 26-38, ISSN 1337-8384.

TESTS, TESTS, TESTS ... Elementary Level, Basic Level, 1 Certification level. 2017. St. Petersburg: Zlatoust.

THE LEXICAL MINIMUM IN RUSSIAN AS A FOREIGN LANGUAGE. The First Certification Level. Common Ownership. 2017. $9^{\text {th }}$ edition. St. Petersburg: Zlatoust.

TYPICAL TESTS IN RUSSIAN AS A FOREIGN LANGUAGE. 2016, Elementary level. Common Ownership. St. Petersburg: Zlatoust.

VLADIMIROVA, T. E., etc. 2001. State Standards on Russian as a Foreign Language. Elementary Level. $2^{\text {nd }}$ ed., rev. and add. Moscow - St. Petersburg: Zlatoust, $28 \mathrm{p}$.

ZIMNAYA, I. A. 1971. Self-Control of the Speaker as One of the Indicators of the Level of Possession of a Foreign Speech. Teaching Foreign Languages in Higher Education. Moscow, pp. 114-121.

Words: 6242

Characters: 40311 (22,39 standard pages)

assoc. prof., candidate of philology Gracheva O.A.

Department of Russian language

Peoples‘ Friendship Univ. Of Russia

10 Miklukho-Maklaya St., Moscow

Russian Federation

gracheva_oa@pfur.ru

senior lecturer Matukhin P.G.

Department of Philology

Peoples' Friendship Univ. Of Russia

10 Miklukho-Maklaya St., Moscow

Russian Federation

matukhin_pg@pfur.ru

assoc. prof., PhD in Pedagogy, Komissarova N.V.

Russian State Social University, Linguistic Faculty,

English Philology Department 
Wilhelm Pieck str., 4, build.3, Moscow

Russian Federation

natalie_komis@mail.ru

project manager Saltykova O.V.

Joint venture Sodruzhestvo, Ltd.

4 Programmers' St., Dubna.

Russian Federation

edu@altden.ru

senior lecturer Kopylova P.A.

Department of Russian language

Peoples' Friendship Univ. Of Russia

10 Miklukho-Maklaya St., Moscow

Russian Federation

kopylova_pa@pfur.ru 